Historia Slavorum Occidentis

2020, $\mathrm{nr} 1$ (24)

ISSN 2084-1213

DOI: $10.15804 /$ hso200102

Pavel Krafl (Warszawa, Nitra)

ORCID 0000-0003-0595-7904

Lenka Blechová (Praga)

\title{
Konfraternia żagańskiego konwentu kanoników regularnych z 1401 roku*
}

Słowa kluczowe: kanonicy regularni św. Augustyna, Żagań, Kłodzko, konfraternia, dokument, średniowiecze

Keywords: Canons Regular of St. Augustine, Żagań, Kłodzko, confraternity, document, Middle Ages

Abstract: In this article, the authors present an edition of preserved and to date unpublished documents demonstrating the origin of confraternities between Convents of Canons Regular in Żagań and in Kłodzko. The documents were issued on 5 and 19 March 1401.

Konwenty kanoników regularnych św. Augustyna zawierały konfraternie, co zobowiązywało ich do sprawowania liturgii, odmawiania modlitw, śpiewu psalmów i odprawiania mszy zadusznych za kanoników z zaprzyjaźnionego konwentu. Klasztory zakonu pod względem prawnym w większości podlegały biskupowi diecezjalnemu, a zakon nie był sterowany centralnie. Konfraternie do pewnego stopnia zastępowały nieistniejące więzi o charakterze administracyjnym; powstawała cała sieć powiązań konfrateryjnych. W niniejszym artykule przedstawimy edycję zachowanych i nie-

* Wkład L. Blechovej jako autorki to efekt realizacji projektu Agencji Grantowej Republiki Czeskiej nr 17-16153S (Grantová agentura ČR, reg. č. 17-16153S). 
publikowanych dotąd dokumentów poświadczających zawarcie konfraterni między konwentami zakonników regularnych w Żaganiu i w Kłodzku w 1401 r.

Odnośnie do literatury na temat dziejów zakonu kanoników regularnych św. Augustyna w krajach czeskich i w Europie Środkowej można odesłać do opublikowanych przeglądów badań ${ }^{1}$. Historię śląskich klasztorów kanoników regularnych św. Augustyna, łącznie z żagańskim klasztorem, opracowała Anna Pobóg-Lenartowicz². Wcześniej historię klasztoru w Żaganiu zebrał w swojej monografii poświęconej tamtejszej bibliotece klasztornej Alfred Świerk ${ }^{3}$. Wyniki badań w postaci dwóch publikacji książkowych na temat dziejów kłodzkiego klasztoru w czasach przedhusyckich przedstawił Pavel Krafl ${ }^{4}$. Stosunki klasztoru kłodzkiego z innymi klasztorami tego zakonu w drugiej połowie XV w. na podstawie kroniki klasztoru w Kłodzku przedstawił Wojciech Mrozowicz 5 . P. Krafl w zwięzły sposób opracował konfraternię klasztoru w Kłodzku ${ }^{6}$. Wiele dokumentów zawarcia konfraterni wydanych przez konwenty z roudnickiego kręgu zakonu kanoników regularnych św. Augustyna zostało częściowo udostępnionych $\mathrm{w}$ formie edycji w poszczególnych artykułach, a ostatnio w dyplomatarzach klasztorów zakonu?

1 P. Krafl, Výzkumy středověkých dèjin středoevropských klášterů řeholních kanovníků sv. Augustina, Acta Universitatis Reginaehradecensis, Facultas Paedagogica - Humanistica 1 (2008), s. 171-182; P. Krafl, „Debemus caritatis operibus ferventer intendere. Výzkumy dèjin řeholních kanovníkůsv. Augustina $v$ Čechách a na Moravě období středověku za uplynulá desetiletí, Časopis Matice moravské 128 (2009), s. 147-169; P.O. Krafl, Ecclesia in Glacz frequencius a Christi fidelibus visitetur. Kapitoly $z$ dějin kladské kanonie v době předhusitské, Brno 2015, s. 13-63.

2 A. Pobóg-Lenartowicz, Kanonicy regularni na Śląku, Opole 1999.

3 A. Świerk, Średniowieczna biblioteka klasztoru kanoników regularnych św. Augustyna w Żaganiu, Śląskie prace bibliograficzne i bibliotekoznawcze 8, Wrocław 1965, s. 21-33.

4 P.O. Krafl, Ecclesia in Glacz, s. 65-145; tenże, Quam ecclesiam in honore sancte Marie Virginis intitulari volumus. Study on the Kłodzko Monastery of Canons Regular of St. Augustine in the PreHussite Period, Canonici regulares sancti Augustini, vol. 1, Brno 2018.

5 W. Mrozowicz, Kronika klasztoru kanoników regularnych w Kłodzku. Ze studiów nad średniowiecznym dziejopisarstwem klasztornym, Wrocław 2001, s. 146-148.

6 P.O. Krafl, Konfraternity kladského kláštera řeholních kanovníků sv. Augustina, Východočeské listy historické 37 (2017), s. 7-13; tenże, Quam ecclesiam, s. 61-68.

7 Zob. dane bibliograficzne opublikowane w artykułe P.O. Krafl, Konfraternity kladského kláštera řeholních kanovníků sv. Augustina, s. 8-9, przyp. 8-14; tenże, Quam ecclesiam, s. 61-62, przyp. 148. - Spis możliwo uzupełnić artykułem z zalącznikem edycyjnym P. Krafl, Listina prostějovských řeholních kanovníku (1403) ze Státního archivu ve Vratislavi, Hereditas monasteriorum 8 (2016), s. 263-268 i edycją Diplomatarium monasterii Glacensis canonicorum regularium sancti Augustini ab anno 1350 usque ad annum 1381, edd. P.O. Krafl, L. Blechová, coop. P. Sedláček, Canonici 
Początki działalności kanoników regularnych św. Augustyna w Żaganiu datują się na rok 1284, kiedy konwent został tu przeniesiony z Nowogrodu Bobrzańskiego. W Żaganiu kanonicy regularni objęli w posiadanie tamtejszy kościół parafialny i kaplice św. Ducha, św. Krzyża i św. Wincentego. Przeniesienie do Żagania z niegościnnego Nowogrodu stanowiło podstawę dalszego rozwoju klasztoru. W czasach opata Piotra (1300-1304) w gestii kanoników regularnych znalazły się majątki miejscowego szpitala. Kaplicą przyszpitalną zarządzał bezpośrednio opat klasztoru ${ }^{8}$. Kanonia kłodzka została założona w 1350 r. Jej fundatorami byli arcybiskup praski Arnošt z Pardubic i jego bracia Smil i Vilém z Pardubic. 23 X 1350 r. wydając odpowiedni dokument ufundowali kanonikom regularnym w Kłodzku kościół Najświętszej Maryi Panny. Darowali im posiadłości w trzech wsiach i w mieście Kłodzku. Karol IV przekazał powstającemu klasztorowi wójtostwo w Szalejowie i w Starkowie. Klasztor założono, aby wyjednać zbawienie dla Arnošta, Smila i Viléma z Pardubic oraz ich rodziców ${ }^{9}$. Jeśli chodzi o związki między żagańskim i kłodzkim klasztorem, to można wspomnieć o działalności Jana II - byłego członka kłodzkiego konwentu, a w latach 1382-1396 prepozyta klasztoru kłodzkiego - w żagańskim konwencie. Po rezygnacji z urzędu prepozyta w 1396 r. odszedł do Żagania ${ }^{10}$.

Konfraternia żagańskiego i kłodzkiego konwentu jest udokumentowana za pośrednictwem odpowiednich dokumentów. Dokument zawarcia konfraterni zawsze wydawał jeden konwent na rzecz drugiego, z pewnymi wyjątkami, kiedy wydawano wspólny dokument dotyczący obu konwentów. W odpowiedzi drugi konwent, po dłuższym lub krótszym czasie, wydawał swój własnym dokument. W zdecydowanej większości przypadków zachował się tylko dokument jednego z konwentów; dokument drugiego konwentu bądź się nie zachował, bądź też nie doszło do jego sporządzenia. Jako wydawcy dokumentów figurują przełożony klasztoru - czyli proboszcz lub opat - i konwent ${ }^{11}$.

regulares sancti Augustini, vol. 2, Brno 2018, s. 106-108, n. 27; s. 137-138, n. 44; s. 139-140, n. 45 .

8 A. Pobóg-Lenartowicz, Kanonicy regularni na Śląsku, s. 51; A. Świerk, Średniowieczna biblioteka, s. 24.

9 P.O. Krafl, Quam ecclesiam, s. 25-28; tenże, Ecclesia in Glacz, s. 67-69; Z. Hledíková, Arnošt z Pardubic. Arcibiskup, zakladatel, rádce, Praha 2008, s. 66-68.

10 Cronica monasterii canonicorum regularium (s. Augustini) in Glacz, ed. W. Mrozowicz, Vratislaviae 2003, s. 9, 10. Srov. P.O. Krafl, Ecclesia in Glacz, s. 102.

11 Srov. P.O. Krafl, Konfraternity kladského kláštera řeholních kanovníkio sv. Augustina, s. 9-10. 
W przypadku omawianej konfraterni żagańskich i kłodzkich kanoników regularnych mamy do dyspozycji dokumenty obydwu konwentów. Pierwszy z dokumentów został wydany 5 III 1401 r. w Kłodzku, jego wydawcą jest proboszcz kłodzkiego klasztoru Piotr (1396-1403) i tamtejszy konwent kanoników regularnych. Zachował się pergaminowy oryginał, który jest przechowywany w Archiwum Państwowym we Wrocławiu Rep. 116 (archiwum żagańskiego klasztoru kanoników regularnych) pod sygnaturą 182 (dawna sygn. 181). Tekst pisany jest bastardą. Na dokumencie - na pasku pergaminowym - znajduje się spiczasto-owalna pieczęć proboszcza i okrągła pieczęć konwentu. Na plice dokumentu jest notatka dotycząca dnia odbywania się anniversarium ${ }^{12}$. Oryginał został skatalogowany przez Romana Stelmacha ${ }^{13}$. Ponadto w zbiorach rękopisów wspomnianego archiwum zachowała się kopia z pierwszej połowy XV w., Rep. 135, sygn. 419. Chodzi o kartulariusz klasztoru w Żaganiu z pierwotną sygnaturą D 289. W górnej części kopii znajduje się napis „Littera fraternitatis canonicorum regularium in Glacz”, oprócz tekstu dokumentu znajdziemy tu także kopię notatki znajdującej się na plice ${ }^{14}$.

Drugi z dokumentów wydano 19 III 1401 r. w Żaganiu; wydawcą jest opat miejscowego klasztoru Ludolf von Einbeck (1394-1422) ${ }^{15}$ i żagański konwent kanoników regularnych. Pergaminowy oryginał jest przechowywany w Archiwum Parafialnym Ojców Jezuitów w Kłodzku, gdzie pod sygnaturą A 81 zdeponowano pierwotne archiwum kłodzkiej kanonii. Na paskach pergaminowych wisi spiczasto-owalna pieczęć opata i okrągła pieczęć konwentu. Na plice znajdują się zapiski o takiej samej treści, jak w przypadku dokumentu kłodzkiego proboszcza i konwentu z 5 III 1401 r. ${ }^{16}$ Oryginał został skatalogowany przez Bertolda Bretholza w odpowiednim tomie serii wydawniczej Geschichtsquellen der Grafschaft Glatz ${ }^{17}$.

W zdecydowanej większości zachowanych dokumentów związanych z konfraterniami zawieranymi między konwentami należącymi do kręgu kanoników regularnych w Roudnicy nad Łabą oraz wielu konwentów spoza tego kręgu, z którym

\footnotetext{
12 Archiwum Państwowe Wrocław, Rep. 116, sygn. 182.

13 R. Stelmach, Katalog średniowiecznych dokumentów przechowywanych w Archiwum Państwowym we Wroctawiu, Wrocław-Racibórz 2014, s. 302, n. 5469.

14 Archiwum Państwowe Wrocław, Rep. 135, sygn. 419, s. 73.

15 Viz A. Pobóg-Lenartowicz, Kanonicy regularni na Śląsku, s. 253; A. Świerk, Średniowieczna biblioteka, s. 26-27.

16 Archiwum Parafialne Kłodzko, sygn. A 81.

17 Geschichtsquellen der Grafschaft Glatz, VI/3 Das Pfarrei-Archiv in Glatz und das Koeglersche Urkunden - und Aktenarchiv in der Pfarrei Ullersdorf, ed. Berthold Bretholz, Glatz 1928, s. 21, n. 112.
} 
konwenty należące do kręgu kanoników regularnych roudnickich były powiązane, powtarza się jednolity schemat tekstowy ${ }^{18}$. Oba dokumenty z 5 i 19 marca są identyczne pod względem treści, jednak ich sformułowania są całkowicie odmienne od schematu przyjętego w kręgu roudnickim. Interesujące jest to, że konwentem, który jako pierwszy wydał odmienny dokument tekstowy, był konwent kłodzki należący do roudnickiej grupy konwentów kanoników regularnych. Kolejne z zachowanych dokumentów wydane przez konwent kłodzki (z 28 X 1376 r. dla konwentu w Třeboniu i z 26 I 1407 r. dla konwentu w podkrakowskim Kazimierzu) pod względem treści odpowiadają normie kręgu roudnickiego ${ }^{19}$. Można przypuszczać, że postać tekstowa dokumentów powstała z inicjatywy konwentu w Żaganiu. Oryginały konfraterni żagańsko-kłodzkiej wydano w ciągu zaledwie czternastu dni ${ }^{20}$. Dzięki zapiskom na plice obu dokumentów wiemy przynajmniej, że anniversarium miało się odbyć 13 maja.

Tłumaczenie z języka czeskiego Elżbieta Baron

Aneks

1.

1401 Mart. 5. Kłodzko.

Petrus praepositus et fratres monasterii sanctae Mariae CRSA in Kłodzko Pragensis dioecesis confraternitatem cum monasterio sanctae Mariae in Żagań contrahunt decernuntque pro fratribus defunctis domorum suarum suffragia in missis, psalmis et orationibusfacere.

\footnotetext{
18 Zob. edycje wymienione w przyp. 7.

19 Národní archiv Praha, AZK, sign. 126; P. Krafl, Dokumenty konfraterni czeskich, morawskich $i$ śląskich klasztorów z pierwszej połowy XV wieku. $Z$ archiwum klasztoru kanoników regularnych laterańskich $w$ Krakowie-Kazimierzu, Rocznik Biblioteki Naukowej PAU i PAN w Krakowie 48 (2003), s. 21-22.

20 Podobnie w przypadku konfraterni klasztoru třeboňskiego i kłodzkiego zawartej w $1376 \mathrm{r}$. dokumenty wydano w ciągu trzynastu dni; P.O. Krafl, Konfraternity kladského kláštera řeholních kanovníku sv. Augustina, s. 12. W innych przypadkach drugi konwent wydawał stosowny dokument po kilku miesiącach czy nawet latach; por. P. Krafl, Dokumenty konfraterni czeskich, morawskich i ślaskich klasztorów, s. 19 (tabelka); P. Krafl, P. Mutlová, D. Stehlíková, Řeholní kanovníci sv. Augustina v Lanškrouně. Déjiny a diplomatář kláštera, Práce Historického ústavu AV ČR, řada B Editiones, vol. 7, Praha 2010, s. 58 (tabelka), s. 59.
} 
Sigg. in scidulis membranaceis appendent: 1. Petri, praepositi monasterii in Kłodzko; 2. conventus eiusdem monasterii.

Autogr. membr. Lat., Archivum publicum in Wroctaw, Rep. 116, sign. 182.

In medio plicae: Diem anniversariam ad Kalendas assignabimus aterciam decimam $^{-a}$ mensis Maii in hac silaba Ser cisioianus immediate post Nerei et Achillei.

In dorso: Litera fraternitatis fratrum in Glacz.

Copia Lat. in ms. saec. XV $V^{\text {in }}$, Archivum publicum in Wroctaw, Rep. 135, sign. 419, p. $73(=B)$.

Ed. -

Reg. Roman Stelmach, Katalog średniowiecznych dokumentów przechowywanych w Archiwum Państwowym we Wrocławiu, Wrocław-Racibórz 2014, p. 302, n. 5469 (sub die erroneo 5 Maii).

Lit. Pavel Otmar Krafl, Konfraternity kladského kláštera řeholních kanovníků sv. Augustina, Východočeské listy historické 37 (2017), p. 9-12; Idem, Quam ecclesiam in honore sancte Marie Virginis intitulari volumus. Study on the Kłodzko Monastery of Canons Regular of St. Augustine in the Pre-Hussite Period, Canonici regulares sancti Augustini, volumen 1, Brno 2018, p. 64, 65, 68.

$\neq \mathrm{V} \neq$ enerabilibus in Christo patribus et dominis domino Ludolfo abbati totique conventui ordinis sancti Augustini canonicorum || regularium in Sagano ${ }^{1}$ frater Petrus prepositus totusque conventus monasterii sancte Marie in $\mathrm{Glacz}^{2}$ canonicorum || regularium Pragensis ${ }^{3}$ dyocesis, quitquid potuerint servicii et honoris. Quamquam dilectissimi sancta mater ecclesia bonorum laborum cottidiana || beneficia, que pro divina laude in salutem tocius sui corporis consuevit peragere in singulos adopcionis filios traducat generaliter, nequaquam tamen catholice religionis sue derogat fastigio, ut specialius caris specialium opitulaminum stipendia largiantur, et dum enim pro condicione et posse bona nostra collata a Deo alter utrum in Christo dividimus non que nostra, ${ }^{b}$ sed que Ihesu Christi sunt agentes in caritatis vinculo mentes 'intimas adunamus; sicque sit, ut quod quasi dividuum et singulare haberi videtur in singulos hac dileccionis unitate proficiat universis. Volentes igitur in Ihesu Christi sanctis sacrificiis, que offerimus vestri devote esse memores, sicut decet, meminisse fratrum talis fraternitatis et amicicie, ${ }^{\mathrm{d}}$ vobiscum contrahimus ${ }^{-\mathrm{d}}$ unionem, quod a data presencium et deinceps annis singulis uno certo constituto die sollempnem anniversarium pro domus vestre singulis fratribus in vigiliis et missa sub nota decantanda, semel dumtaxat in anno tam humiliter quam constanter per nos et posteros nostros inperpetuum observemus. Ceterum, si unius vel plurium congregacionis 
vestre fratrum obitus recens, quem Deus felicem faciat, nobis fuerit intimatus, salvis generaliter superius expressatum, unusquisque sacerdotum in privato ad duas missas legendas, vero sacerdos ad duas quinquagenas ${ }^{\mathrm{e}}$ psalmorum dicendas, ${ }^{-\mathrm{e}}$ laycus autem conversus ad orandas centum oraciones dominicas sint astricti. Si qui vero fratrum ex devocione premissis aliquit [!] adiciendo facere composuerint devocionis execucionem impedire nolumus, sed laudando prosequi volumus ac fideliter confovere. In cuius rei testimonium presentes sigillorum nostrorum iussimus munimine roborari. Actum et datum in Glacz anno Domini ${ }^{\mathrm{f}}$ millesimo $\mathrm{CCCC}^{\mathrm{mo}}$ primo, ${ }^{-\mathrm{f}}$ Sabbato ante Dominicam, qua Oculi ${ }^{\mathrm{g}} \mathrm{mei}$ in ecclesia Domini decantatur.

a-a) „XIII ${ }^{\text {am“ }}$ B. $-{ }^{b)}$ „nostra sunt" B. - ${ }^{c)}$ „nostras“ B. - ${ }^{d-d)}$ „contrahimus vobiscum“ B. $-{ }^{e-e)}$ „dicendas psalmorum“ B. $-{ }^{f-f)}$ „M CCCCI ${ }^{\circ “}$ B. $\left.-{ }^{g}\right)$ „Domini“ cancellatum B.

1) Żagań, civitas in Silesia. $-{ }^{2)}$ Kłodzko, civitas in terra Glacensi. $-{ }^{3)}$ Praha, civitas in Bohemia, caput regni.

2.

1401 Mart. 19. Żagań.

Ludolfus abbas et fratres monasterii sanctae Mariae CRSA in Żagań Wratislaviensis dioecesis confraternitatem cum monasterio sanctae Mariae in Kłodzko contrahunt decernuntque pro fratribus defunctis domorum suarum suffragia in missis, psalmis et orationibus facere.

Sigg. in scidulis membranaceis appendent: 1. Ludolfi, abbatis monasterii in Żagań; 2. conventus eiusdem monasterii.

Autogr. membr. Lat., Archivum parochiale in Kłodzko, sign. A 8 l.

In medio plicae: Diem anniversariam ad Kalendas assignabimus XIII mensis May in hac sillaba Ser in cisioianus inmediate post Nerei et Achillei.

In dorso: Psalmi Verba mea commendacio. Unius vel plurium missa, in qui sub [nota q...]. Quilibet presbyter unam missam. Accoliti, subdiaconi II quinquagenas [...]. Laici conversi centum Pater noster. - Alia manu: Littera fraternitatis Saganenssium.

Ed. -

Reg. Geschichtsquellen der Grafschaft Glatz, VI/3 Das Pfarrei-Archiv in Glatz und das Koeglersche Urkunden - und Aktenarchiv in der Pfarrei Ullersdorf, ed. Berthold Bretholz, Glatz 1928, p. 21, n. 112. 
Lit. P. O. Krafl, Konfraternity kladského kláštera, p. 9-12; Idem, Quam ecclesiam, p. 62, 64, 65, 68 .

$\neq \mathrm{V} \neq$ enerabilibus in Christo patribus et dominis domino Petro preposito totique conventui ordinis sancti Augustini canonicorum regularium || in Glacz ${ }^{1}$ frater Ludolfus abbas totusque conventus monasterii sancte Marie in Sagano ${ }^{2}$ canonicorum regularium Wratisslaviensis ${ }^{3}$ || dyocesis, quitquid potuerint servicii et honoris. $\mathrm{Qu}$ amquam dilectissimi sancta mater ecclesia bonorum laborum cottidiana beneficia, que pro divina || laude in salutem tocius sui corporis consuevit peragere in singulos adopcionis filios traducat generaliter, nequaquam tamen catholice religionis sue derogat et fastigio, ut specialius caris specialium opitulaminum stipendia largiuntur, dum enim pro condicione et posse bona nostra collata a Deo alter utrum in Christo dividimus non que nostra, sed que Ihesu Christi sunt agentes in caritatis vinculo mentes intimas adunamus; sicque sit, ut quod quasi dividuum et singulare haberi videtur in singulos hac dileccionis unitate proficiat universis. Volentes igitur in Ihesu Christi sanctis sacrificiis, que offerimus vestri devote esse memores, sicud [!] decet, meminisse fratrum talis fraternitatis et amicicie, vobiscum contrahimus unionem, quod a data presencium et deinceps annis singulis uno certo constituto die sollempnem anniversarium pro domus vestre singulis fratribus in vigiliis et missa sub nota decantanda, semel dumtaxat in anno tam humiliter quam constanter per nos et posteros nostros in perpetuum observemus. Ceterum, si unius vel plurium congregacionis vestre fratrum obitus recens, quem Deus felicem faciat, nobis fuerit intimatus, salvis generaliter superius expressatis, unusquisque sacerdotum in privato ad duas missas legendas, vero sacerdos ad duas quinquagenas psalmorum dicendas, laycus autem conversus ad orandas centum oraciones dom[inicas sint astricti]. Si qui vero fratrum ex devocione premissisa liquid adiciendo facere proposuerint devocionis execucionem [impedire nolumus] sed laudando prosequi volumus ac fideliter confovere. In cuius rei testimonium presentes sigillorum nostrorum iussimus munimine roborari. Actum et datum in Sagano anno Domini millesimo $\mathrm{CCCC}^{\mathrm{mo}}$ primo, Sabbato ante Dominicam, qua Iudica in ecclesia Domini decantatur.

1) Kłodzko, civitas in terra Glacensi. - ${ }^{2)}$ Żagań, civitas in Silesia. $-{ }^{3)}$ Wroctaw, civitas in Silesia. 


\section{Summary}

Convents of Canons Regular of St. Augustine entered into confraternity with each other, which consisted of performing church service acts and memorial services on behalf of canons regular from an affiliated convent. In this article we provide an edition of documents demonstrating the origin of confraternity between convents of canons regular in Żagań and in Kłodzko in 1401. The first of these documents was iss ued on 5 March 1401 by the provost and convent in Kłodzko. The document has been preserved in form of the original parchment, which is stored in the State Archive in Wroclaw in fund Rep. 116 under number 182. The second of these documents was issued on 19 March 1401 by the abbot and convent in Żagań. The parchment original is stored in the Parish Archive in Kłodzko, under number A 8 1. Both documents, from 5 and 19 March, contain identical text.

Translated by Ewa Dratwa

Prof. PhDr. Pavel Otmar Krafl, Dr.

Instytut Historii im. Tadeusza Manteuffla Polskiej Akademii Nauk

Rynek Starego Miasta 29/31

02-272 Warszawa

Polska

Filozofická fakulta Univerzity Konštantína Filozofa

Hodžova 1

94974 Nitra

Slovensko - Słowacja

e-mail: paotk@seznam.cz

Lenka Blechová, Ph.D.

Historický ústav Akademie věd ČR

Prosecká 76

19000 Praha

Česká republika - Czechy

e-mail: tullius72@hotmail.com

Nadesłany 10 XI 2019

Nadesłany po poprawkach recenzyjnych 30 XI 2019

Zaakceptowany 10 I 2020 